\title{
Further Contributions to the Geological History of the British Flora.
}

\author{
BY \\ CLEMENT REID, F.L.S., F.G.S.
}

THE past ten years have yielded much information which They have witnessed so great an accumulation of evidence relating to the origin of the British flora, to the climatic changes which expelled or brought back this flora, and to the means of dispersal by which our plants were able to regain their lost position, that the subject is no longer within the compass of an article in a scientific journal. I am compelled, therefore, to reserve all details for publication in bookform; but as the volume cannot be completed for another year, I have in this paper tabulated some of the leading results.

Before entering into details as to the range in time of our British plants, it may be useful in a few words to summarize the results now arrived at. This will be done without touching more than is necessary on the various debatable conclusions to which the researches seem to lead. The notes

1 Annals of Botany, Vol. ii, p. 177. No. VI, Ang. 1888.

[Annale of Botany, Vol. XII. No. XIVI. June, 1808.] 
shall be confined as far as possible to the facts, and to such inferences as to former climatic changes as seem to follow necessarily from a study of the botanical evidence. Without some idea of the prehistoric state of Britain the records would be of little value. I doubt whether many, even of the geologists, have realized that ceaseless ebb and flow which prevents our fauna and flora from exhibiting more than the rudest adaptation to the present state of Britain. Possibly in some part of the Tropics a balance may have been arrived at; but in Britain the last climatic changes have taken place at too recent a date for such a result, and the composition of our flora is still undergoing constant modification.

About one-seventh of our flowering plants have now been found in the fossil state. This is by no means a large proportion; yet considering that fully a third of our species have neither deciduous leaves, woody stems, nor hard seeds, and are unlikely therefore to be often preserved as fossils, it is not unsatisfactory. The orders are very unequally represented. In the first place, annual plants with soft seeds are almost entirely absent. Orders such as the Cruciferae and Orchideae are wanting; Grasses are found, but only as indeterminable nodes or leaves. These deficiencies are easy to understand; but the absence of Leguminosae and of the aquatic species of Veronica and Scrophularia is less comprehensible, and makes one speculate as to whether the deficiency is real, or in part due to the more perishable nature of the pods and seeds, though these may seem quite hard enough to be preserved. The orders best represented are mainly those which possess hard fruits or seeds specially adapted for dispersal, and those with deciduous leaves. Ranunculaceae, Caryophyllaceae, Rosaceae, Cupuliferae, Naiadaceae and Cyperaceae are all fairly well represented; Umbelliferae are not uncommon, though seldom in a determinable state. Fruits of Compositae are characteristic and do not readily decay; various species belonging to this order have been discovered, but they are usually represented by a few wind-borne specimens. The order is likely to yield 
an exceptionally complete record; its entire absence from the older Tertiary deposits is therefore all the more striking.

The deposits from which existing species of plants have been obtained in Northern Europe may be grouped roughly into four series; but as the number of cold or warm waves that have passed since Pliocene times is still uncertain, the classification adopted is provisional, and may need to be considerably extended. The provisional grouping used in this paper is as follows:-

Neolithic:-Post-Glacial,but Pre-Roman. 'Submerged forests,' and alluvial or lacustrine deposits with a Temperate flora. Cultivated plants and weeds of cultivation appear. (Part of the Scottish plant-bearing strata may be of more recent date.)

Late Glacial:-Lacustrine deposits with Arctic plants, above the latest deposits showing ice-action.

Interglacial:-Deposits with Temperate plants, between strata indicating Arctic conditions.

Early Glacial:-Flood-loams with Arctic plants, at the base of the Glacial deposits of Norfolk.

Preglacial:-Newest Pliocene deposits (Cromer Forest-bed).

A word of warning is perhaps needed as to the use of the table for the determination of species as 'native' or 'introduced.' The term native though convenient is misleading, for it is doubtful whether a single one of our flowering plants is really native of Britain. The whole flora has originated probably in other and various parts of the world. We find now merely the species stranded by successive waves of migration, which have brought together a variety of continental forms, some Arctic, some Southern, a few even American. These migrations were mainly compelled by climatic changes, though other agencies have played an important part. To judge by the evidence already obtained, though negative evidence does not go for much, it seems probable that a far larger proportion of our plants was introduced by human agency than has been thought. 
TABLE SHOWING THE GEOLOGICAL RANGE OF THE RECENT BRITISH FLORA.

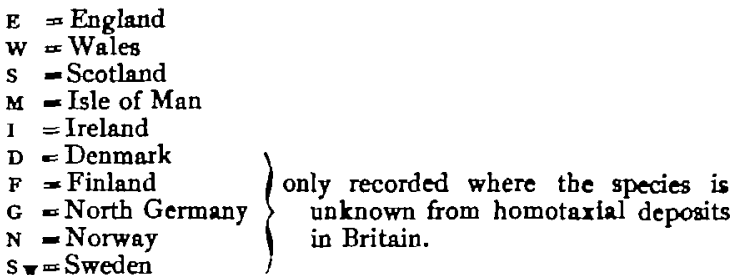
$S=-$ Sweden

\begin{tabular}{|c|c|c|c|c|c|c|c|c|}
\hline - & & & & 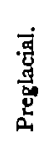 & 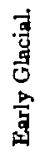 & $\begin{array}{l}\text { 胥 } \\
\text { 恶 } \\
\text { 总 } \\
\text { 点 }\end{array}$ & 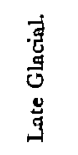 & 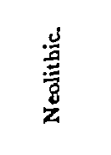 \\
\hline $\begin{array}{l}\text { Clematis Vitalba, L. . } \\
\text { Thaliclrum minus, L. }\end{array}$ & $\dot{.}$ & $\cdot \dot{ }$ & : & $\cdots$ & $\ddot{k}$ & $\begin{array}{c}\text { E ? } \\
\ldots\end{array}$ & $\mathbf{S}$ & \\
\hline , favwm, L. & . & .. & . & $\dddot{E}$ & $\ldots$ & E & $\cdots$ & \\
\hline Ranuncwlus aquatilis, L. & . & - $\cdot$ & - & $\mathbf{R}$ & $\mathbf{E}$ & E S & E $\mathrm{s}$ & E S I $\mathrm{M}$ \\
\hline$" \quad$ sceleratus, L. & - & - & • & $\cdots$ & .. & E & $\mathbf{E}$ & \\
\hline Flammula, L. & - & - & . & ... & ... & $\mathbf{E}$ & E & S M \\
\hline Lingrua, L. . & • & $\cdot$ & * & ... & .. & $\mathbf{E}$ & $\ldots$ & \\
\hline repers, L. & - & . & - & $\mathrm{E}$ & $\ldots$ & E & E S & $E S M$ \\
\hline bullbosus, L. . & $\cdot$ & - & - & ... & $\ldots$ & $\mathbf{E}$ & & \\
\hline Sardous, Crant & & - & - & $\cdots$ & ... & H & & \\
\hline $\begin{array}{l}\text { parviforws, } \mathrm{L} \text {. } \\
\text { Caltha palustris, L. }\end{array}$ & . & : & $\dot{5}$ & $\begin{array}{c}\mathrm{E} \\
\mathrm{E}\end{array}$ & $\begin{array}{l}\cdots \\
\ldots\end{array}$ & $\begin{array}{l}\mathrm{E} \\
\mathrm{E}\end{array}$ & $\mathbf{E}$ & $\mathbf{s}$ \\
\hline Nuphat luteum, Sm. . . & $\cdot$ & - & . & $\boldsymbol{E}$ & ... & $\mathbf{E}$ & $\cdots$ & $\mathbf{E}$ \\
\hline Nymphaca alba, L. . . . & $\cdot$ & - $\cdot$ & - & ... & ... & G & ... & S- \\
\hline Papaver somniferum, L. . & $\cdot$ & - $\cdot$ & - & $\cdots$ & ... & $\cdots$ & ... & $\mathbf{s}$ \\
\hline Fumaria officinalis, L. . & - & • & - & ... & ... & $\cdots$ & ... & $\mathbf{s}$ \\
\hline Cakile martitima, Scop. . & - & . & - & $\cdots$ & $\cdots$ & $\cdots$ & $\cdots$ & Sw \\
\hline Viola palustris, L. . . & . & - & . & $\mathbf{E}$ & ... & E S & E s & $\mathbf{S} \mathbf{M} \mathbf{W}$ \\
\hline Silene maritima, L $\cdot$ & $\cdot$ & - & - & $\cdots$ & $\cdots$ & $\mathbf{R}$ & & \\
\hline Lychnis alba, Mill. . & . & • & - & .. & $\ldots$ & $\therefore$ & $\cdots$ & $\mathbf{s}$ \\
\hline " diuma, Sibth. & . & - & • & $\cdots$ & ... & ... & $\mathbf{s}$ & $\mathbf{s}$ \\
\hline \#̈ Floscuculi, L.. • & - & - & - & $\cdots$ & ... & $\ldots$ & $\mathbf{s}$ & $\mathbf{s}$ \\
\hline Stollaria aquatica, Scop. . & - & - & • & $\mathbf{E}$ & & & & \\
\hline "media, Cyr. . & - & • & : & $\mathbf{E}$ & $\cdots$ & H & E S & $\mathbf{s}$ \\
\hline Arenaria trinervia, L. & $\dot{0}$ & i. & • & $\cdots$ & $\begin{array}{l}\cdots \\
\cdots\end{array}$ & $\ddot{G}$ & $\cdots$ & $\mathbf{s}$ \\
\hline Spergula arversis, $\mathbf{L}$. . & . & . & . & $\ldots$ & $\ldots$ & ... & & $\mathbf{s}$ \\
\hline Moniza fontana, L. . : . & $\therefore$ & - & - & ... & ... & E & $\mathbf{E}$ & $\mathbf{s}$ \\
\hline Hyperioum quadrangulum, & L. & - & - & $\cdots$ & $\cdots$ & $\cdots$ & $\because$ & $\mathbf{s}$ \\
\hline "' elodes, L . . & $\cdot$ & • & & $\cdots$ & $\cdots$ & $\cdots$ & $\therefore$ & $s$ \\
\hline Tilia platyphyllas, Scop. . & . & - & & .. & ... & G & & Sw \\
\hline Linum, sp. - $\cdot \cdot^{\cdot}$ & . & 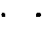 & - & ... & ... & $\cdots$ & ... & $\mathbf{s}$ \\
\hline Geraninm columbinum, L & · & - $\cdot$ & & $\cdots$ & $\cdots$ & G & & 8 \\
\hline $\begin{array}{l}\text { Oxalis Acelosella, L } \\
\text { Ilex Aquifolium, }\end{array}$ & $\cdot$ & • & • & $\cdots$ & $\cdots$ & $\ddot{G}$ & & $\begin{array}{l}\text { E S } \\
\text { E }\end{array}$ \\
\hline Rhaminss Frangula, L . & & & & $\ldots$ & $\ldots$ & E & $\ldots$ & sw \\
\hline
\end{tabular}




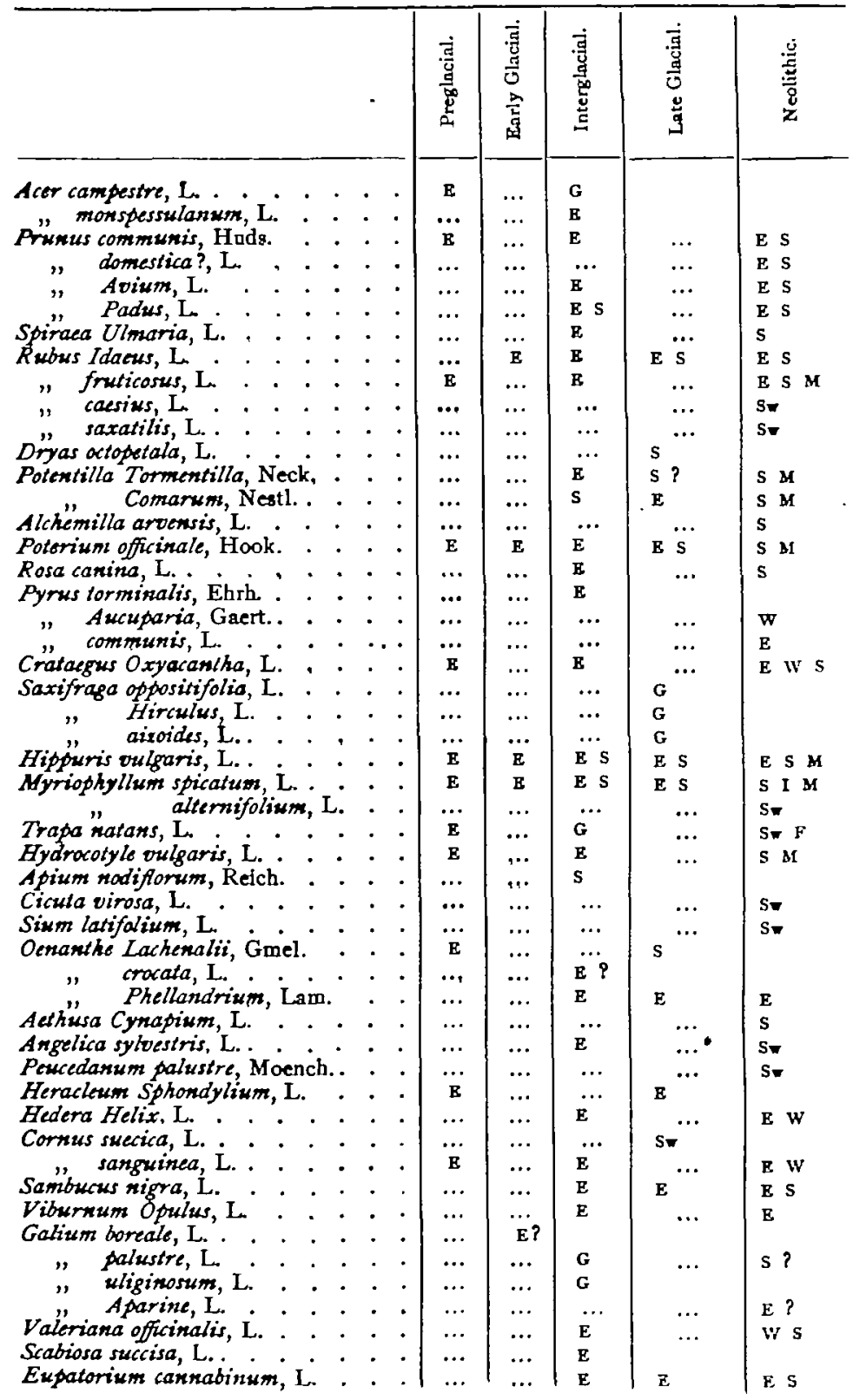




\section{Reid.-Further Contributions to the}

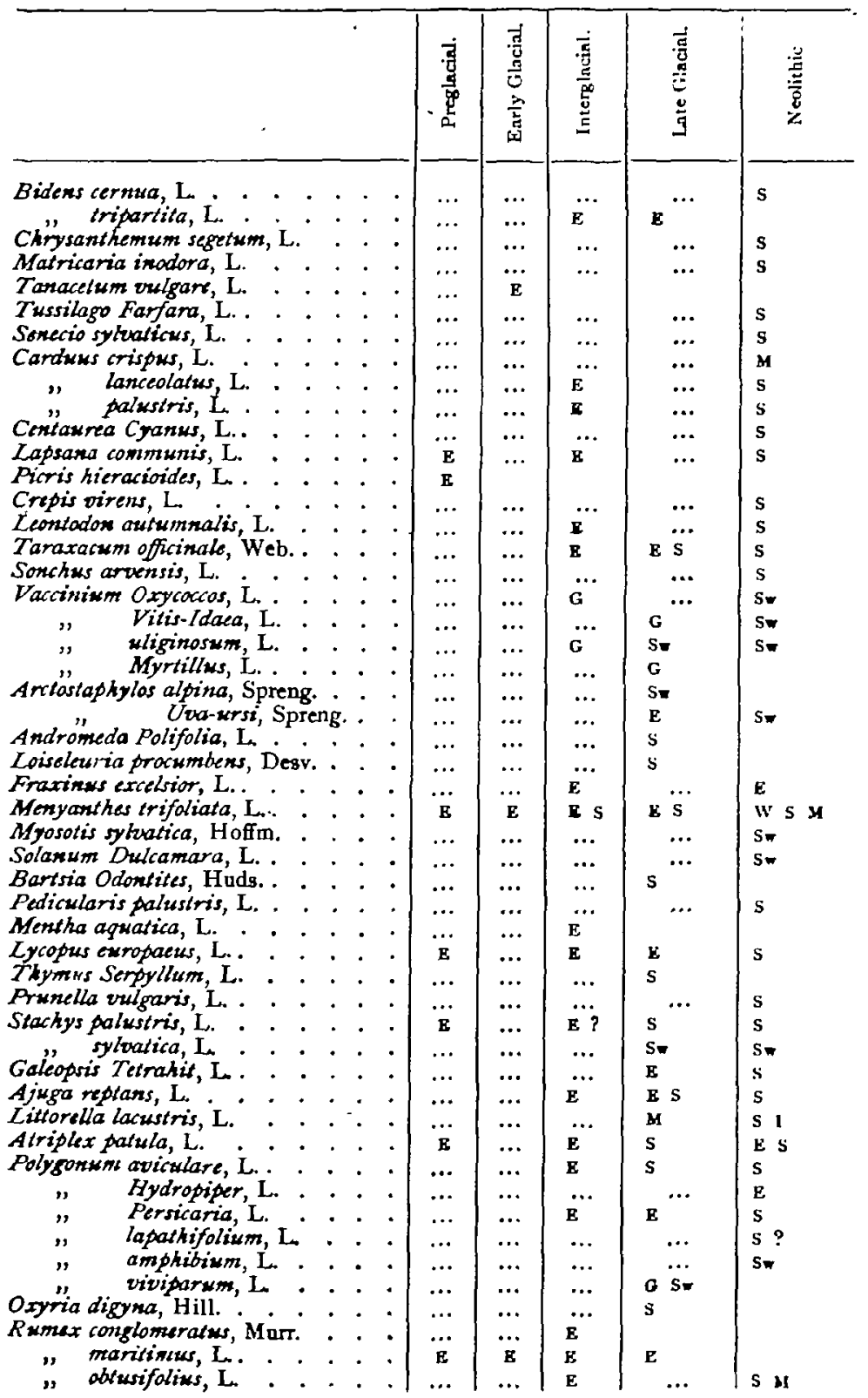




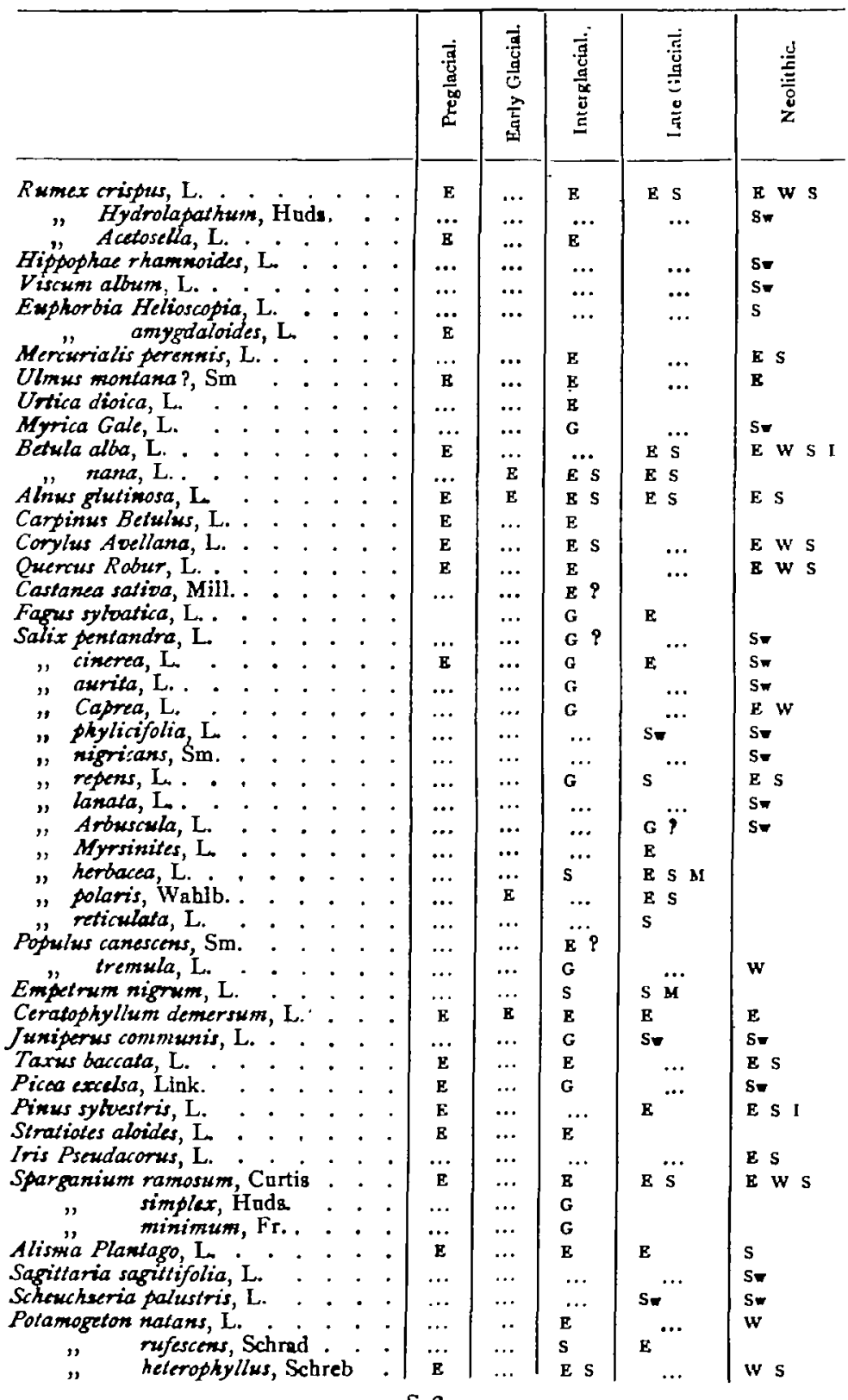


250 Reid.-Geological History of the British Flora.

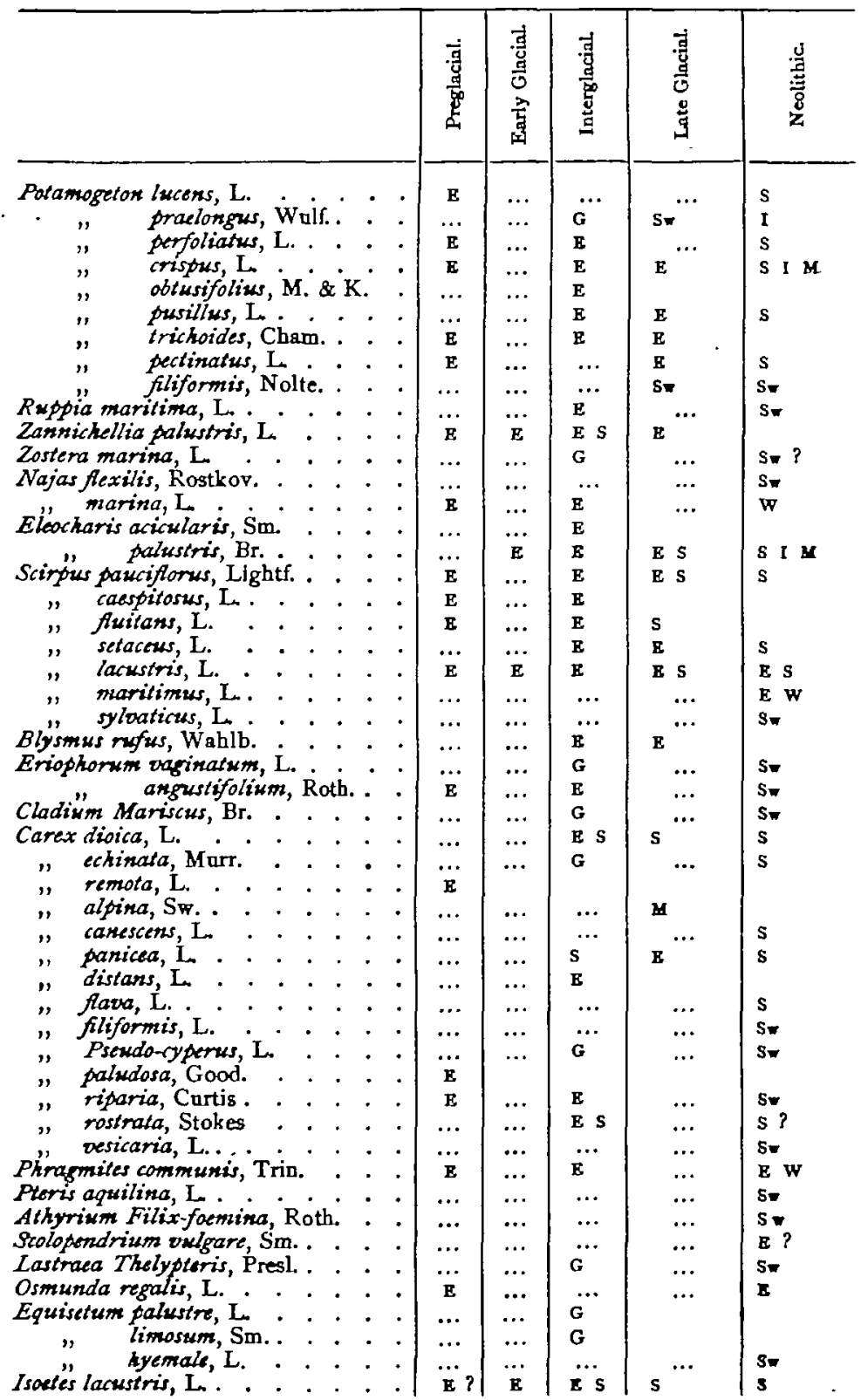

